\title{
Regression Equation from Dual Energy X Ray Absorptiometry (DEXA) for Estimating Muscle Mass Segment
}

\author{
Ecuación de Regresión de la Absorciometría de Energía Dual de Rayos X (DEXA) para la \\ Estimación de Segmento de Masa Muscular
}

"Fernando Javier Rodríguez Rodríguez; ${ }^{* *}$ Atilio Aldo Almagiá Flores \& ${ }^{* * * *}$ Francisco José Berral de la Rosa

RODRÍGUEZ, R. F. J.; ALMAGIÁ, F. A. A. \& BERRAL, D. L. R. F. J. Regression equation from dual energy X ray absorptiometry (DEXA) for estimating muscle mass segment. Int. J. Morphol., 30(2):550-556, 2012.

SUMMARY: Anthropometric methods used to estimate muscle mass (MM) do not specify values for body segments, a critical fact for individuals practicing physical activities or clinical diagnosis. In this study, 60 recreational athletes are anthropometrically evaluated and also undergo dual energy X-ray absorptiometry. Linear regression statistics is subsequently used to establish the constants allowing the obtaining of the segment MM. Three equations were obtained, one for the upper members: MMUL $=(0.533 * \mathrm{FAP})-$ $(0.176 * \mathrm{RAP})+(0.42 * \mathrm{WP})+(0.282 * \mathrm{SRL})-19,985$; a second equation for muscle mass of the lower members: $\mathrm{MMLL}=(0.186 * \mathrm{H})-$ $\left(0.158^{*} \mathrm{LTTL}\right)-(0.024 * \mathrm{LTL})+\left(0451^{*} \mathrm{LP}\right)-24.535$; and the third one for the muscle mass of the trunk $\mathrm{TrMM}=\left(0.026^{*} \mathrm{~W}\right)+\left(0.046^{*} \mathrm{H}\right)$ $+(0.154 * \mathrm{TTD})+\left(0.025^{*} \mathrm{NP}\right)-\left(0.025^{*} \mathrm{AP}\right)-5.839$. These equations enable getting detailed information on the MM distribution through an easy-to-access and fast technique, such as the anthropometry, from a Gold Standard Method like DEXA.

KEY WORDS: Anthropometry; Muscle mass; DEXA.

\section{INTRODUCTION}

Evaluation through the DEXA method results to be a very precise and valid form for estimating the fat mass and the fat-free mass.

The method shows such accuracy that it has already started to replace health indexes, such as the Body Mass Index, by the fat index as a better indicator (Vasconcelos et al., 2010), as it also shows adiposity in each body area, which is different for each individual. This difference may indicate the mortality risk associated to a high adiposity (Auyeung et al., 2009).

The DEXA method accuracy allows assessing the body composition for different individuals (Rodriguez et al., 2010), sedentary, athletes of all disciplines and ages and chronically sick people.

Fat-free mass given by the DEXA method permits estimating the body mass and the bone mineral content (Williams et al., 2006; Eisenmann et al., 2004; Flegal et al.,
2009) with a low variation coefficient (between $1 \%$ and 4\%) in the different components of the individuals and a minimal $\mathrm{X}$-ray exposure, thus making it a non-invasive technique (van der Ploeg et al., 2003; Eston et al., 2005), consequently becoming the reference method par excellence (Visser et $a l ., 2003$ ) and one of the most accurate for the estimation of muscle mass (Freda et al., 2009), which is even borne out by the European Society for Clinical Nutrition and Metabolism as a reference method for the evaluation of body composition.

Muscle mass measured through DEXA is also used for the diagnosis of the presence of Sarcopenia with a section of $<6.32 \mathrm{~kg} / \mathrm{m}^{2}$ of muscle mass. Under this value, it causes a series of metabolic and hormonal disorders (Baumgartner et al., 1998; Melton et al., 2000; Szulc et al., 2004).

However, this is a hard-to-reach method in Chile, as it is exclusively used in the clinical field for the diagnosis of diseases, such as osteoporosis and osteopenia, and includes

\footnotetext{
* Escuela de Educación Física, Facultad de Filosofía y Educación, Laboratorio Motricidad Humana. Laboratorio de Antropología Física y Anatomía Humana, Instituto de Biología, Facultad de Ciencias, Pontificia Universidad Católica de Valparaíso. Chile.

** Laboratorio de Antropología Física y Anatomía Humana, Instituto de Biología, Facultad de Ciencias, Pontificia Universidad Católica de Valparaíso. Chile.

${ }^{* * *}$ Departamento de Deporte e Informática, Facultad del Deporte, Universidad Pablo de Olavide, España. Colaborador Laboratorio de Antropología Física y Anatomía Humana, Instituto de Biología, Facultad de Ciencias, Pontificia Universidad Católica de Valparaíso. Chile.
} 
a significant amount of equipment and volume that make transportation difficult. Furthermore, it involves a high cost for those population studies including many individuals. The latter gives the anthropometric technique a high strength, which is fast, easy to transport and significantly cheaper and with a reduced evaluation period.

The anthropometric technique becomes even more significant when estimating the segment muscle mass through a Gold Standard method, as shown in this study.

\section{SUBJECTS AND METHODS}

Sixty recreational athletes frequently exercising (6$12 \mathrm{hr}$ per week), with $24.6 \pm 4.1$ average age were evaluated. All athletes volunteered under informed consent and considering the Declaration of Helsinki, and agreed to the study as a random and deliberate sample.

Anthropometric Evaluation. The Gaucho Pro "Mercosur" kit was used for the anthropometric method, which is manufactured in Argentina under the license of Rosscraft Canada for its marketing in the American Continent (except US, Canada and Mexico). The anthropometric kit includes the following instruments: Campbell 20 (long Anthropometer), Campbell 10 (short Anthropometer), Segmometer, set square, Skinfold Caliber, metric tape for perimeters, a stadiometer for height and a weight scale.

The anthropometric evaluation was done early in the morning, with little clothing as possible and after a urinary emptying and under the marking protocol of the International Society for the Avancement of Kineatropometry (ISAK) and evaluation protocols described by Drinkwater (1984) and Ross et al. (2002) for the complete variable protocol.

Data collection was provided by the assistant helping the evaluator to record the data. This assistant was aware of the measurement techniques, thus promoting a fluent work that guaranteed the correct sequence of the measuring spots.

The data collection or proforma sheet was designed to improve the measurement speed, and is ordered from the upper to the lower anatomic position.

Three different basic variables were measured: weight, standing height and sitting height, 9 bone diameters, 14 perimeters, 8 skinfolds and 8 longitudes.

DEXA Evaluation. A complete clinical evaluation of the body through DEXA was carried out on the same day to determine the fat-free bone mass and the fat with the Lunar DPX-MD model from Lunar Radiation Corporation, Madison, WI, USA.

The individuals were located in a dorsal decubitus position, with their arms located at one side of the body and the lower limbs extended, at rest and semi-separated.

The evaluation is done with a scanning of the whole body following the instructions and protocols of the manufacturer, where a mobile arm in a craniocaudal and lateral direction where the X-ray source performing the body scanning, and the emerging radiation detector to cross the tissues are located. The X-ray source emits a two-level frequency: $76 \mathrm{KeV}$ and $41.1149 \mathrm{KeV}$.

Results of the body composition are obtained using the Antropogym software.

The variable analysis and the linear regression statistics application allowing the obtaining of the bone mass estimating formulas are done using the SPSS software in Spanish, version $\mathrm{N}^{\circ} 17$.

The statistic significance level of the data differences and correlations is accepted with a p lower than 0.05 with the previous program.

The Lunar Spectacullar Imaging software is used for both the DEXA evaluation and issuing of results, including the evaluation equipment itself.

The DEXA method determines the adipose mass (AM), fat-free mass (FFM) and dry bone mass (DBM). The latter only represents the bone mineral content, so an estimation of the total bone mass (TBM) is required, dividing the DBM by 0.55 or multiplying it by 1.82 (Heymsfield et al., 1990).

Body limbs are made from muscle mass (MM), AM and bone mass $(\mathrm{BM})$. Once this value is determined, the FFM value is subtracted and then the MM value of the limb is obtained, i.e.:

Total Mass: $\mathrm{AM}+\mathrm{FFM}$, where FFM= BM + MM and MM= FFM - DBM

The muscle mass of the trunk area is obtained calculating the total muscle mass from the total fat free mass, using the equation:

Total Muscle Mass $(\mathrm{TMM})=(1.19-\mathrm{FFM})-1.01$ (Kim et al., 2002). 
The muscle mass of the upper limb (MMUL) and the muscle mass of the lower limb (MMLL) are subsequently added up, and the TMM is then subtracted following the next equation:

Trunk Muscle Mass $(\operatorname{TrMM})=\mathrm{TMM}-(\mathrm{MMUL}+\mathrm{MMLL})$

The anthropometric predictor model is created through the correlation of the muscle mass results of each area with the 42 measured anthropometric variables. After the variables included in each area are clearly determined, a "Principal Component Analysis" (PCA) is carried out in order to reduce the dimensionality of the explicative variables.

Finally, the anthropometric variables shown in table I are obtained, which will be used as variables for each estimating equation.

\section{RESULTS}

Estimation of the MM per segment. Variables with high correlation with the MM result obtained by DEXA in each segment are chosen for the estimation of the MMUL, MMLL and TrMM.

The following constants are obtained using the linear regression equations for each variable (Table II).

Therefore, it is plausible to develop equations to estimate the MMUL, MMLL and TMM that result in the following:
1) $\mathrm{MMUL}=(0.533 * \mathrm{FAP})-(0.176 * \mathrm{RAP})+(0.42 * \mathrm{WP})+$ $(0.282 *$ SRL $)-19,985$

Where, FAP= Flexed Arm Perimeter; RAP= Relaxed Arm Perimeter; WP= Wrist Perimeter; $\mathrm{SRL}=$ Styloid Radio Length.

2) $\mathrm{MMLL}=(0.186 * \mathrm{H})-\left(0.158^{*} \mathrm{LTTL}\right)-(0.024 * \mathrm{LTL})+$ $(0451 *$ LP $)-24.535$

Where, H= Height; TTL= Lateral Tibia Throcanter Length; LTL= Lateral Tibia Length; LP= Leg Perimeter.

3) $\operatorname{TrMM}=(0.026 * \mathrm{~W})+(0.046 * \mathrm{H})+(0.154 * \mathrm{TTD})+$ $(0.025 * \mathrm{NP})-(0.025 * \mathrm{AP})-5.839$

Where, $\mathrm{W}=$ Weight; $\mathrm{H}=$ Height; $\mathrm{TD}=$ Transverse Thorax Diameter; $\mathrm{NP}=$ Neck Perimeter; $\mathrm{AP}=$ Abdominal Perimeter

Considering the results presented in all three scenarios, i.e. nearly $25 \%$ of the predictive variables of each case was enough to explain the behavior of the dependent variables, and also taking into account the use of a dimensional reduction analysis (DRA) as those variables with good correlations did not show the best results with DEXA, the multiple regression analysis was carried out, which involved all measured variables.

The predictive variables showed a linear relation with the independent variables in all three scenarios, or in another words, there is Multi-colinearity of the predictive variables (a variable is explained or depends on one of more of the remaining variables).

Table I. Correlated variables used for the development of the regression equations to estimate the segment components.

\begin{tabular}{|c|c|c|c|}
\hline & VARIABLES & $\mathbf{R}$ & $\overline{\mathbf{R}^{2}}$ \\
\hline \multirow{4}{*}{ UPPER LIMB } & Relaxed arm perimeter & 0.6 & 0.4 \\
\hline & Flexed arm perimeter & 0.7 & 0.5 \\
\hline & Wrist perimeter & 0.4 & 0.2 \\
\hline & Radio-styloid length & 0.5 & 0.3 \\
\hline \multirow{4}{*}{ LOWER LIMB } & Height & 0.7 & 0.5 \\
\hline & Thochanter and tibia length & 0.5 & 0.2 \\
\hline & Lateral tibia length & 0.2 & 0.1 \\
\hline & Leg perimeter & 0.7 & 0.5 \\
\hline \multirow{5}{*}{ TRUNK } & Weight & 0.7 & 0.5 \\
\hline & Height & 0.8 & 0.6 \\
\hline & Transverse thorax diameter & 0.8 & 0.6 \\
\hline & Neck perimeter & 0.4 & 0.2 \\
\hline & Abdominal perimeter & 0.4 & 0.1 \\
\hline
\end{tabular}


RODRÍGUEZ, R. F. J.; ALMAGIÁ, F. A. A. \& BERRAL, D. L. R. F. J. Regression equation from dual energy X ray absorptiometry (DEXA) for estimating muscle mass segment. Int. J. Morphol., 30(2):550-556, 2012.

Table II. Coefficients for the development of the estimating equations for each segment.

\begin{tabular}{lcccrr}
\hline & non-stand Coeff. & \multicolumn{2}{c}{ Stand. Coef. } & \\
\cline { 1 - 3 } Model & B & $\begin{array}{l}\text { Stand. } \\
\text { Error }\end{array}$ & Beta & t & \multicolumn{1}{c}{ Sig. } \\
(Constant) & $-19,985$ & 1,526 & & $-13,095$ & 0 \\
Relaxed arm & $-0,176$ & 0,079 & $-0,432$ & $-2,235$ & 0,029 \\
Flexed arm & 0,533 & 0,084 & 1,212 & 6,352 & 0 \\
Wrist perimeter & 0,42 & 0,079 & 0,287 & 5,32 & 0 \\
Rardio-Styloid & 0,282 & 0,044 & 0,348 & 6,384 & 0 \\
(Constant) & $-24,535$ & 3,724 & & $-6,588$ & 0 \\
Height & 0,186 & 0,033 & 0,678 & 5,604 & 0,029 \\
Throchanter and tibia length & $-0,158$ & 0,069 & $-0,261$ & $-2,291$ & 0,026 \\
Lateral tibia length & $-0,024$ & 0,027 & $-0,069$ & -0.896 & 0,374 \\
Leg perimeter & 0,451 & 0,07 & 0,524 & 6,463 & 0 \\
(Constant) & $-5,839$ & 1,689 & & $-3,457$ & 0,001 \\
Weight & 0,026 & 0,012 & 0,282 & 2,222 & 0,03 \\
Height & 0,046 & 0,01 & 0,428 & 4,793 & 0 \\
Thorax diameter & 0,154 & 0,044 & 0,347 & 3,507 & 0,001 \\
Neck perimeter & 0,025 & 0,027 & 0,087 & 0,955 & 0,344 \\
Abdominal perimeter & $-0,025$ & 0,015 & $-0,176$ & $-1,656$ & 0,104 \\
\hline
\end{tabular}

(non-stand. Coeff. = non-standard Coefficient; Stand. Coeff. = Standard Coefficient; B = Constant to be used for each variable; Stand. Error $=$ Standard Error; Beta $=$ Beta value; $\mathrm{t}=\mathrm{t}$ value; Sig. $=$ statistical significance $)$.

\section{DISCUSSION}

The estimated muscle mass for the designed regression formulas promote the specific knowledge of the muscle component and allow comparing the differences between rugby and soccer players, for example, where significant differences in the muscle mass of the upper limb may be found, assuming the rugby player needs better muscle development in his arms and forearm than an average soccer player (Barraza et al., 2009) or compared to other collective sports, such as basketball, volleyball or handball (Bayios et al., 2006; Carvajal et al., 2009; Gholami \& Rad, 2010, Papadopoulou \& Papadopoulou, 2010), individual sports (Sanchez-Muñoz et al., 2006; Kong \& Heer, 2008; Knechtle et al., 2010a; Knechtle et al., 2010b; Bejan, 2010; Borgard, 2010) or between collective and individual sports. These formulas also allow establishing differences in the athlete himself, in different temporal moments, trained or untrained, injured or under normal performance conditions, etc.

Such information results significant for advanced adults, where the high muscle mass plays an important role (Wannamethee et al., 2007; Szulc et al., 2010), acknowledging some physical activities develop a distinct muscle mass distribution. In this group the muscle mass of the lower extremities represents more than half of the total muscle mass, so sports promoting the development this muscles, such as running, soccer or cycling (Knechtle et al., 2007) may result advantageous and more efficient to prevent sarcopenia compared to other sports that involve a higher muscle mass development of the upper limbs or trunk, like swimming or rowing, for example (Andreoli et al., 2001).

When the results of the three equations designed for each segment are sum up, a value $r=0.9$ is shown for the DEXA method considering the following equation:

\section{Total Muscle Mass $=$ MMUL + MMLL + TrMM}

The adequate correlations resulting through the equations developed in this study suggest the values estimated involve a low error in the estimation of each segment, being $0.38 \mathrm{~kg}$ for the MMUL, $1.07 \mathrm{~kg}$ for the MMLL and $0.37 \mathrm{~kg}$ for the TrMM, although when the error percentages for each segment are observed, they seem to be higher (Fig. 1; Table III).

Table III shows the good correlations found in this group, which show a great response to the muscle mass estimation through appendicular and trunk segments, however they are not perfect. 
The intended selection of the study group complied with certain homogeneous characteristics such as health state and physical activity levels. Although with an age range between 19 and 34 years old which may influence the results according to expertise and number of years dedicated to physical activity which favors an increase of muscle mass, therefore returning to the heterogeneous sample with respect to muscle mass quantity, considering the 19-year old individual has less muscle development than an individual with vast physical activity.

One of the strengths of this age group is that it represents the age of most active athletes (McIntyre \& Hall, 2005; Duthie et al., 2006; Almagià et al., 2009; Rossi et al., 2010; Gholami et al.,2010), allowing a better comparison and correlation with this group of individuals under study.

Therefore, unlike other studies involving inactive and older individuals these formulas permit a more precise estimation of athlete's muscle mass without overestimating it, as occurs in other equations.

However, the need for future studies which include a vast age range of subjects is clear, as is the need to obtain precise equations for each age group with different characteristics, including type of sport, such as long distance runners, sprinters or force athletes and also the different levels of physical activities in recreational, amateur and professional athletes.

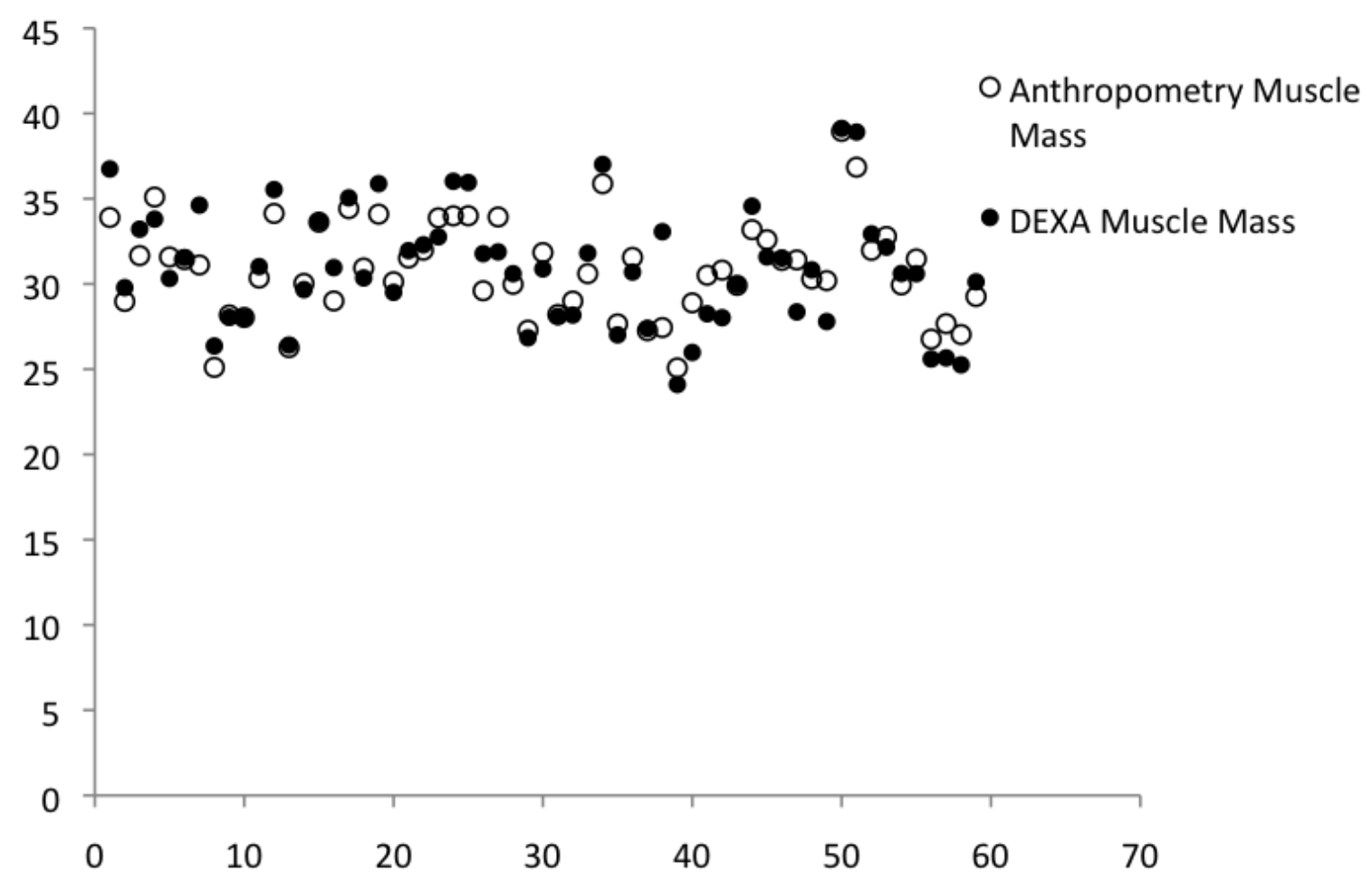

Fig. 1. Muscle mass $(\mathrm{kg})$ of the individuals obtained through DEXA and estimated by the suggested anthropometric model $(\mathrm{R}=0.9)$.

Table III. Equation correlations and standard errors for the upper (MMUL) and lower extremities (MMLL) and trunk (TrMM) compared to the DEXA method.

\begin{tabular}{lcccc}
\hline Model & $\mathbf{R}$ & $\mathbf{R} 2$ & Standard Error $(\mathbf{k g})$ & Error \% \\
\hline MMUL & 0.93 & 0.87 & 0.38 & $6 \%$ \\
MMLL & 0.85 & 0.72 & 1.07 & $6 \%$ \\
TrMM & 0.89 & 0.79 & 0.37 & $5 \%$ \\
\hline
\end{tabular}


ACKOWLEDGEMENTS: The authors would like to acknowledge all the participants evaluated during this study, the Escuela de Educación Física for the constant support, the Physical Anthropology and Human Anatomy Laboratory and the Dirección Investigación e Innovación of the Pontificia Universidad Católica de Valparaíso.

RODRÍGUEZ, R. F. J.; ALMAGiá, F. A. A. \& BERRAL, D. L. R. F. J. Ecuación de regresión de la absorciometría de energía dual de Rayos X (DEXA) para la estimación de segmento de masa muscular. Int. J. Morphol.,

RESUMEN: Métodos antropométricos eran usados para estimar la masa muscular (MM) no especificando valores para segmentos de cuerpo, un hecho crítico para individuos que practican actividades físicas o el diagnóstico clínico. En este estudio, 60 atletas recreacionales son evaluados antropometricalmente y por absorciometría de energía dual de Rayos X. La estadística de regresión lineal posteriormente es usada para establecer el constante el permiso de la obtención del mm de segmento. Tres ecuaciones fueron obtenidas, un para los miembros superiores: MMUL $=(0.533 * \mathrm{FAP})-(0.176 * \mathrm{RAP})+(0.42 * \mathrm{WP})+(0.282 * \mathrm{SRL})-19,985$; una segunda ecuación para la masa muscular de los miembros superiores: MMLL $=(0.186 * \mathrm{H})-(0.158 *$ LTTL $)-(0.024 * \mathrm{LTL})+(0451 * \mathrm{LP})-24.535 ; \mathrm{y}$ una tercera para la masa muscular del tronco: $\operatorname{TrMM}=(0.026 * \mathrm{~W})+(0.046 * \mathrm{H})+(0.154 * \mathrm{TTD})+(0.025 * \mathrm{NP})-(0.025 * \mathrm{AP})-5.839$. Estas ecuaciones permiten la adquisición de la información detallada sobre la distribución de MM por una técnica de acceso fácil y rápido, como la antropometría, de un Método de Gold Estándar como DEXA.

PALABRAS CLAVE: Antropometría; Masa muscular; DEXA.

\section{REFERENCES}

Almagià, F. A. A.; Rodríguez, R. F.; Barrraza, G. F. O.; Lizana, A. P. J.; Ivanovic, M. D. \& Binvignat, G. O. Perfil antropométrico de jugadores profesionales de voleibol sudamericano. Int. J. Morphol. 27(1):53-7, 2009.

Andreoli, A.; Monteleone, M.; Van Loan, M.; Promenzio, L.; Tarantino, U. \& De Lorenzo, A. Effects of different sports on bone density and muscle mass in highly trained athletes. Med. Sci. Sports Exerc,; 33 (4):507-11, 2001.

Auyeung, T. W.; Lee, J. S. W.; Leung, J.; Kwok, T.; Leung, P. C. \& Woo, J. Survival in older men may benefit from being slightly overweight and centrally obese-a 5-year follow-up study in 4,000 older adults using DXA. J. Gerontol. A Biol. Sci. Med. Sci., 65:99-104, 2009.

Barraza, G. F.; Hadler, G. A.; Jeria, F. J. \& Riffo, E. C. Cuantificación de la masa muscular de los miembros apendiculares, por medio ecuaciones antropométricas. Rev. Motr. Hum., 10 (2):44-8, 2009.

Baumgartner, R. N.; Koehler, K. M.; Gallagher, D.; Romero, L.; Heymsfield, S. B.; Ross, R. R.; Garry, F. J. \& Lindeman, R. D. Epidemiology of sarcopenia among the elderly in New Mexico. Am. J. Epidemiol., 147:755-63, 1998.

Bayios, I.; Bergeles, N.; Apostolidis, N.; Noutsos, K. \& Koskolou, M. Anthropometric, body composition and somatotype differences of Greek elite female basketball, volleyball and handball players. J. of Sports Medicine and Physical Fitness, 46(2):271-80, 2006.

Bejan, A.; Jones, C. \& Jordan, C. The evolution of speed in athletics: why the fastest runners are black and swimmers white. Int. J. Design \& Nature, 50: 1-13, 2010.
Borgard, C. P. Assessing Body Composition Among Male Collegiate Runners and Swimmers. Using Dual-Energy Xray Absorptiometry (DXA). A Thesis of Master of Science in Kinesiology. California Polytechnic State University, 2010 .

Carvajal, W.; Ríos, A.; Echevarría, I.; Martínez, M.; Miñoso, J. \& Rodríguez, D. Body Type and Performance of Elite Cuban Baseball Players. MEDICC Review, 11(2): 15-20, 2009.

Drinkwater, D. T. An anatomically deroved method for the anthropometric estimation of human body composition. Ph. D. Thesis. Simon Fraser University. 1984.

Duthie, G. M.; Pyne, D. B.; Hopkins, W. G.; Livingstone, S. \& Hooper, S. L. Anthropometry profiles of elite rugby players: quantifying changes in lean mass. Br. J. Sports Med., 40:2027, 2006.

Eisenmann, J. C.; Heelan, K. E. \& Welk, G. J. Assessing Body Composition among 3- to 8-Year-Old Children: Anthropometry, BIA, and DXA. Obesity Research, 12:163340, 2004.

Eston, R. G.; Rowlands, A. V.; Charlesworth, S.; Davies, A. \& Hoppitt, T. Prediction of DXA-determined whole body fat from skinfolds: importance of including skinfolds from the thigh and calf in young, healthy men and women. European J. of Clinical Nutrition, 59:695-702, 2005.

Flegal, K. M.; Shepherd, J. A.; Looker, A. C.; Graubard, B. I.; Borrud, L. G., Ogden, C. L.; Harris, T. M.; Everhart, J. E. \& Schenker, N. Comparisons of percentage body fat, body mass index, waist circumference, and waist-stature ratio in adults. Am. J. Clin. Nutr., 89:500-8, 2009. 
Freda, P. U.; Shen, W.; Reyes-Vidal, C. M.; Geer, E. B.; AriasMendoza, F.; Gallagher, D. \& Heymsfield, S. B. Skeletal muscle mass in acromegaly assessed by magnetic resonance imaging and dual-photon x-ray absorptiometry. J. Clin. Endocrinol. Metab., 94(8):2880-6, 2009.

Gholami, M. \& Rad, L. S. Anthropometric, Body Composition and somatotype differences of Iranian elite female basketball and handball players. Br. J. Sports Med., 44(14):19-20, 2010.

Heymsfield, S. B.; Smith, R.; Aulet, M.; Bensen, B.; Lichtman, S.; Wang, J. \& Pierson, R. N. Appendicular skeletal muscle mass: measurement by dual-photon absorptiometry. Am. J. Clin. Nutr., 52:214-8, 1990 .

Kim, J.; Wang, Z.; Heymsfield, S. B.; Baumgartner, R. N. \& Gallagher, D. Total-body skeletal muscle mass: estimation by a new dualenergy x-ray absorptiometry method. Am. J. Clin. Nutr., 76:37883, 2002.

Knechtle, B.; Baumann, B.; Knechtle, P. \& Rosemann, T. What influences race performance in male open-water ultra-endurance swimmers: anthropometry or training? Human Movement, 11(1):91-5, 2010a.

Knechtle, B.; Duff, B.; Amtmann, G. \& Kohler, G. Cycling and running performance, not anthropometric factors, are associated with race performance in a Triple Iron Triathlon. Res. Sports Med., 15:25769, 2007.

Knechtle, B.; Wirth, A.; Baumann, B.; Knechtle, P.; Rosemann, T. \& Senn, O. Differential correlations between anthropometry, training volume, and performance in male and female Ironman triathletes. J. Strength Cond. Res., 24(10): 2785-93, 2010b.

Kong, P. W. \& Heer, H. Anthropometric, Gait And Strength Characteristics Of Kenyan Distance Runners. J. of Sports Science and Medicine, 7:499-504, 2008.

McIntyre, M. C. \& Hall, M. Physiological profile in relation to playing position of elite college Gaelic footballers. Br. J. Sports Med., 39:264-6, 2006.

Melton, L. J.; Khosla, S.; Crowson, C. S.; O'Connor, M. K.; O'Fallon, W. M. \& Riggs, B. L. Epidemiology of sarcopenia. J. Am. Geriatr. Soc., 48:625-30, 2000.

Papadopoulou, S. K. \& Papadopoulou, S. D. Nutritional status of top team-sport athletes according to body fat. Nutrition \& Food Science, 40(1):64 -73, 2010.

Rodríguez, R. F. J.; Almagià, F. A. A. \& Berral, R. F. J. Estimación de la masa muscular de los miembros apendiculares, apartir de densitometría fotónica dual (DEXA). Int. J. Morphol., 28(4):1205-10, 2010.

Ross, W. D.; Carr, R. V.; Carter, J. E. L. \& Guelke, J. Anthropometry Fundamentals. An illustrated guide for precision anthropometry. Turnpike Electronic Publications Inc. www.rosscraft.ca. 2002.
Rossi, L.; Candelária, V. K. C. G. \& Gomes, P. S. Anthropometric and nutritional profile of male mountain bikers. Brazilian Journal of Biomotricity, 4(3):180-9, 2010.

Sánchez-Muñoz, C.; Sanz, D. \& Zabala, M. Anthropometric characteristics, body composition and somatotype of elite junior tennis players. Br. J. Sports Med., 41(11):793-9, 2007.

Szulc, P.; Duboeuf, F.; Marchand, F. \& Delmas, P. D. Hormonal and lifestyle determinants of appendicular skeletal muscle mass in men: the MINOS study. Am. J. Clin. Nutr., 80(2):496-503; 2004.

Szulc, P.; Munoz, F.; Marchand, F.; Chapurlat, R. \& Delmas, P. Rapid loss of appendicular skeletal muscle mass is associated with higher all-cause mortality in older men: the prospective MINOS study. Am. J. Clin. Nutr., 91(5):1227-1236, 2010.

van Der Ploeg, G. E.; Gunn, S. M.; Withers, R. T. \& Modra, A. C. Use of anthropometric variables to predict relative body fat determined by a four compartment body composition model. Eur. J. Clin. Nutr., 57:1009-16, 2003.

Vasconcelos, F. A. G.; Cordero, B. A.; Rech, C. R. \& Petroski, E. L. Sensitivity and specificity of the body mass index for the diagnosis of overweight/obesity in elderly. Cad. Saúde Pública, 26 (8):1519-27, 2010.

Visser, M.; Pahor, M. \& Tylavsky, F. One- and two-year change in body composition as measured by DXA in a population-based cohort of older men and women. J. Appl. Physiol., 94:2368-74, 2003.

Wannamethee, S. G.; Shaper, A. G.; Lennon, L. \& Whincup, P. H. Decreased muscle mass and increased central adiposity are independently related to mortality in older men. Am. J. Clin. Nutr., 86:5 1339-46, 2007.

Williams, J. E.; Wells, J. C. K.; Wilson, C. M.; Haroun, D.; Lucas, A. \& Fewtrell, M. S. Evaluation of Lunar Prodigy dual-energy Xray absorptiometry for assessing body composition in healthy persons and patients by comparison with the criterion 4component model. Am. J. Clinical Nutrition, 83:1047-54, 2006.

\author{
Correspondence to: \\ Fernando Rodríguez Rodríguez \\ Avda. El Bosque 1290 \\ Valparaíso \\ Casilla 4059 \\ Pontificia Universidad Católica de Valparaíso \\ CHILE.
}

Email: fernando.rodriguez@ucv.cl

Received: 26-12-2011

Accepted: 27-02-2012 